\title{
Analysis of the Local Energy Potential Connection with Power Plants Based on Archimedes Turbine $10 \mathrm{~kW}$
}

\author{
Yosi Apriani ${ }^{1}$, Zulkiffli Saleh ${ }^{2}$, Riyan Kurnia Dillah ${ }^{3}$, Ian Mochamad Sofian ${ }^{4}$ \\ 1, 2, 3 Program Studi Teknik Elektro, Universitas Muhammadiyah Palembang,Palembang, Indonesia \\ ${ }^{4}$ Program Studi Teknologi Nautika, Politeknik Transportasi SDP Palembang, Indonesia \\ Yosi_Apriani@um-palembang.ac.id, zulkifflisaleh64@gmail.com, dillahriyan@gmail.com, ian.msof@gmail.com
}

\begin{abstract}
Research on the availability of water potential for the development of power plants with various scales and types of power plants has been done. Since most existing water sources have small discharges and low heads, this study aimed at designing a micro-hydropower center as one of the ways the electrical energy crisis could be avoided, with one of the renewable energy potentials, namely the potential energy of water in Micro Hydro Power Plant. Further studies were related to water resources to Micro Hydro Power Plants (MHPP) construction, especially Archimedes screw turbines guide parameters that corresponded to flow velocity, channel crosssection, and flow volume. It aimed to connect the local energy potential to the output power of the Archimedes screw turbine. The methods used for this study were 1 . Observation 2. Data collection, and 3. Data Analysis. The study was carried out using an observation method that adopted field data collection techniques assisted by measuring equipment to collect data coverage that refers to related parameters. The power available on the channel resulted was $946 \mathrm{~kW}$, and the power generated in the turbine was $5.9 \mathrm{~kW}$.
\end{abstract}

Keywords-power available, power generated in the Archimedes turbine.

\section{INTRODUCTION}

The largest natural resource potential that Indonesia has is water, yet the use of this potential is still limited to the fulfillment of daily life. The energy content of water flowing from a certain height at a certain amount can be used as an alternative to electricity generation [1] - [5]. A water turbine is one of the techniques used to convert the potential energy of water into mechanical energy. Mechanical energy can be further converted to electricity. Renewable electricity generation using small hydropower is known as the Mini Hydro Power Plant (MHPP) [6] - [8].

Nature is very rich in potentials to be used as a source of electrical energy, such as the water sources as a micro-hydro power center [8] - [10]. Most existing water sources only have small discharges and low heads; therefore, the authors seek to design a micro hydropower center as one of the ways the electricity crisis can be avoided adopting one of the potential renewable energy potentials that is water potential in Micro hydro power plant (MHPP) [8].

Currently, energy consumption uses a lot of fossil energy as a primary energy, including the use of energy in the country. Its use continues to increase, while the supply is limited. There is, therefore, a need to take steps to save fossil energy, one of the steps that can be taken is the development and utilization of renewable energy sources. Water as a renewable energy source is a potential target point that can be optimally utilized. The other derivative of the electrical power generation system is MHPP [11]-[13].

\section{LITERATURE REVIEW}

Electrical energy is a primary need. Every country consequently competes for the construction and development of power plants, according to the geographical conditions and the available natural resources. Indonesia has many energy sources that can be utilized such as water (micro-hydro), solar [12], [14], [15], geothermal, and wind [12], [16] - [19]. Efforts to develop a power plant are in line with suggestions to encourage the development of renewable energy, namely the reduction of coal energy sources [16], [20] - [23].

\section{A. Micro Hydro Power Plant (MHPP)}

Micro hydro power plant (MHPP) is an alternative to small-scale electricity generation with a power output of $\leq$ $100 \mathrm{~kW}$, utilizing water resources/potentials such as river flow, irrigation, and waterfall. The development of MHPP is more likely in residential areas or locations in remote areas. Some technical reasons related to the development of MHPP are 1 . The diverse scale of the potential of local sources of energy, 2. SES distribution, 3. Social aspects related to the community's adaptive attitude to the availability and utilization of energy, 4. The amount of investment in MHPP. The direct effect of the amount of power that will be generated is related to the amount of investment from planning to system utilization.

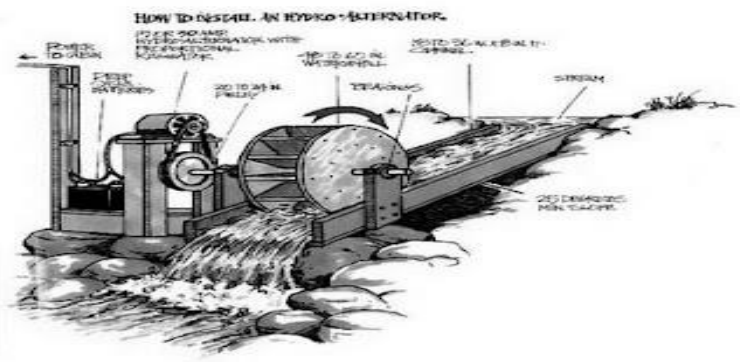

Fig. 1. MHPP 


\section{B. Work Principle of MHPP}

The working principle of MHPP is to take advantage of the height difference and the amount of water per second in the river flow. Water flowing through the intake and the carrier channel to the penstock that will rotate the turbine shaft to produce mechanical energy. Turbines will turn generators and generate electricity.

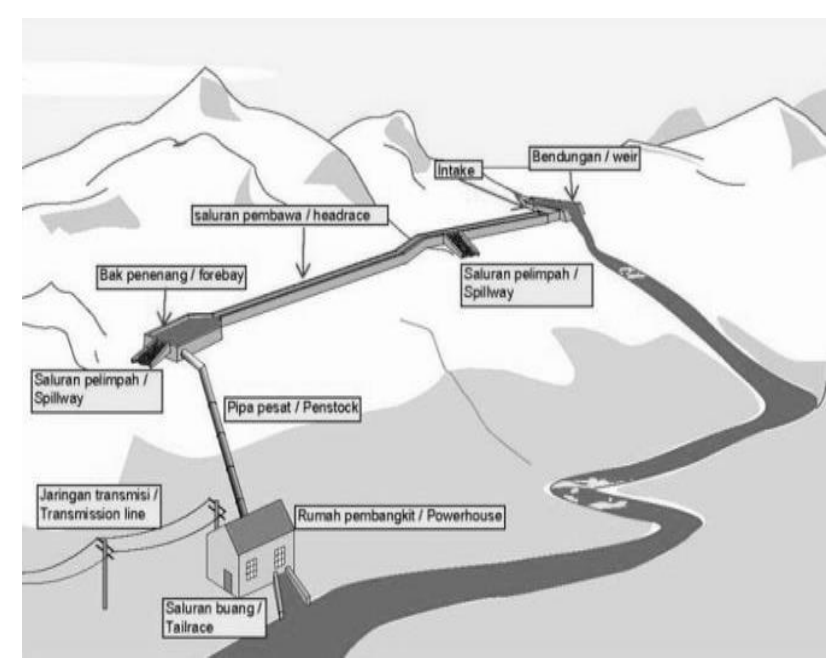

Fig. 2. MHPP System Chart

\section{Water Turbine}

A water turbine is a device for converting water energy into rotary energy. This rotary energy is then converted to electrical energy by a generator. Water turbines were developed in the 19th century and have been widely used for power generation based on the operating principle of turbines for converting the potential energy of water to kinetic energy [24].

Water energy utilization is essentially the use of gravitational potential energy. The mechanical energy of water flow, which is the transformation of gravitational potential energy, is used to drive turbines or windmills. Generally, turbines are used to generate electricity while the wheels are used directly for mechanical energy purposes. Water turbine technology is the advancement of the water wheel. The main difference between the water wheel and water turbine is that the water wheel only changes the flow velocity, while the water turbine changes the direction and the flow velocity.

\section{The working principle of water turbine}

The operating principle of a water turbine is to convert the potential energy of water into mechanical energy. Mechanical energy is converted into electrical power by an electrical generator, based on the turbine's operating principle for converting potential water energy into an energy mechanism. The water flow potential energy enters the turbine runner blades. The rotation of the blades will cause the turbine shaft to move, and then an electrical generator converts the rotary energy into electrical energy.

\section{E. Advantages and disadvantages of water turbines}

Viewed in terms of capital, the use of a water turbine requires a small investment. It is one way to overcome the low-cost electricity crisis, easy maintenance, and an electrical energy crisis saving. Yet, if the turbine rotation is low, the power produced is also low.

\section{F. Archimedes Screw Turbine}

Archimedes screw is a type of screw turbine that has been known since ancient times and has been used as irrigation pumps in Babylonian hanging gardens [25] - [27]. It was once very well known to Roman engineers. This pump was designed by Archimedes which aimed to elevate water from the river. Due to the energy crisis occurred in the world and the limited potential of high headed water energy, an engineer, in 2007, found that water flow could control a pump to convert the potential energy of water flow into mechanical energy. A generator placed above the pump used mechanical energy supplied by the water pump, which caused the flow of electric charge. This flow of electric charge was the output electric current supplied by the generator.

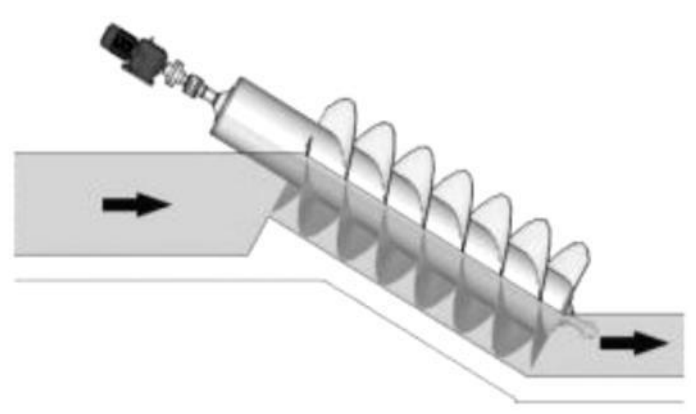

Fig. 3. Archimedes Turbine Screw

\section{G. Turbine Power and Efficiency}

The power produced by the turbine is defined as the work carried out by the water weighing $\mathrm{m}(\mathrm{kg})$ in which, due to the acceleration of the Earth's gravity, the waterfalls at the higher place reach the lowest area where the turbine is installed. The water flowing Q (m3/s) between the turbine blades creates forces with a certain rotational speed at the turbine blades.

The following equations calculate the power produced by a turbine with a certain efficiency.

Pth = p.g.Q.h. $\eta$

with,

Pth $=$ Turbine Power $($ Watt $(\mathrm{W}))$

$\rho=$ density of water $[\mathrm{kg} / \mathrm{m} 3]$

$\mathrm{Q}=$ Debit $[\mathrm{m} 3 / \mathrm{s}]$

$\mathrm{g}=$ Acceleration of gravity [m/s2]

$\mathrm{H}=$ "net head"/effective height.

Efficiency is obtained by equation:

$\eta=$ Pout/Pin $.100 \%$

with,

$\eta \quad=$ Efficiency

Pout $=$ Power out 
Pin $=$ Power in

\section{H. Flow Capacity}

River flow discharge measurements are usually carried out using a buoy and stopwatch measurements, made at a certain point and can be calculated using the following formula:

$\mathrm{Q}=\mathrm{A} \cdot \mathrm{V}$

with,

$\mathrm{Q}=$ water discharge, $\mathrm{m} 3 / \mathrm{s}$

$\mathrm{V}=$ Speed, $\mathrm{m} / \mathrm{s}$

$\mathrm{A}=$ Cross-sectional area, $\mathrm{m} 2$.

\section{Power Available}

Power available is the power that could be produced by the turbine at the time of designing the turbine. The following equation determines the power produced by a turbine with a certain efficiency.

Pth $=$ rg Q.H.h

with,

Pth = Turbine Power $($ Watt $(\mathrm{W}))$

$\rho=$ density of water $[\mathrm{kg} / \mathrm{m} 3]$

$\mathrm{Q}=$ Debit $[\mathrm{m} 3 / \mathrm{s}]$

$\mathrm{g}=$ Acceleration of gravity $[\mathrm{m} / \mathrm{s} 2]$

$\mathrm{H}=$ "net head"/effective height

The efficiency of turbines ranges from $75 \%$ to $90 \%$, depending on the type of turbine (a large turbine will have the highest efficiency).

\section{J. Turbine Power}

The power generated by the turbine can be determined by the following equation (Saleh \& Syafitra, 2016).

$P t=f($ n2).r. $2 \pi n / 60$

with,

Pt $\quad=$ Turbine Power (Watt)

$f(n 2)=$ function $n$,

$\mathrm{N} \quad=$ turnine shaft $\operatorname{spin}$

$r \quad=$ pulley diameter $(\mathrm{m})$

\section{RESEARCH METHOD}

\section{A. Fishbone Diagram}

The data collection techniques depended on the characteristics of variable data, so the techniques used were not always the same for every variable as shown in figure 4 . The study was conducted through an observation method that adopted field data collection techniques assisted by measuring equipment to collect data coverage referring to related parameters.

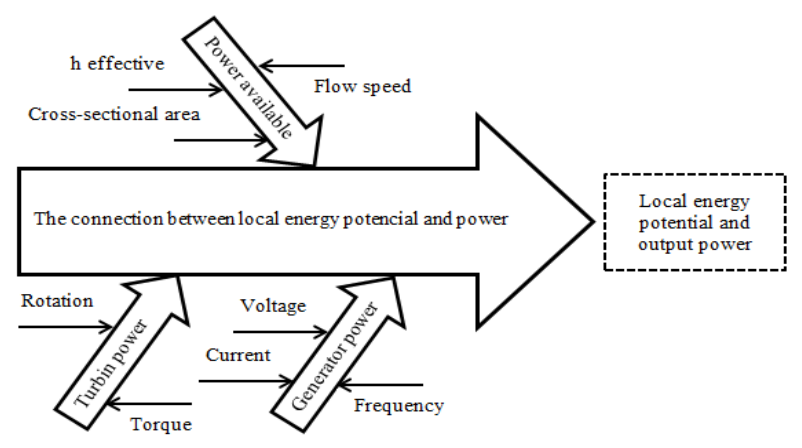

Fig. 4. Fishbone Diagram

\section{RESSULT AND DisCUSSION}

\section{A. Data}

The study focused on the parameters inherent in the Archimedes turbine. The parameter segmentation is adopted from resource measurement data in the field with a review of its derived calculations.

\section{B. Channel data}

Flow data collection in the cross-channel was carried out in the watershed with a moderately good flow potential. The measurements were carried out at 10 (ten) sample point measurements taken to be the basis for calculation at the channel cross-section measurement point.

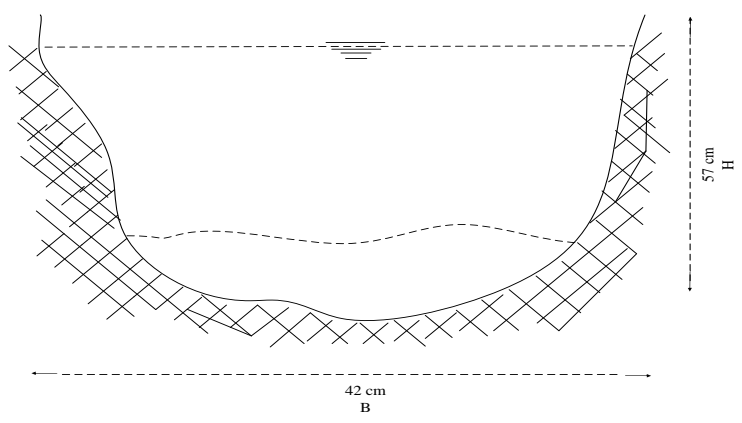

Fig. 5. Channel section

TABLE I. SECTION DATA FLOW

\begin{tabular}{ccccc}
\hline & & $\mathrm{B}=42$ & $\mathrm{H}=57$ & \\
\hline Cross section & $\mathrm{VA}$ & $\mathrm{VB}$ & $\mathrm{VC}$ & $\mathrm{VD}$ \\
\hline 1 & 13,30 & 10,10 & 10,60 & 2,70 \\
\hline 2 & 11,20 & 12,60 & 9,60 & 2,40 \\
\hline 3 & 10,70 & 10,50 & 10,40 & 1,90 \\
\hline 4 & 10,50 & 11,80 & 10,10 & 2,00 \\
\hline 5 & 11,10 & 10,00 & 10,60 & 2,60 \\
\hline 6 & 11,20 & 10,60 & 9,90 & 2,30 \\
\hline 7 & 10,50 & 11,30 & 9,80 & 2,60 \\
\hline 9 & 10,30 & 11,20 & 9,90 & 2,30 \\
\hline 10 & 10,60 & 9,50 & 9,70 & 2,40 \\
\hline Average value & 11,00 & 11,30 & 10,00 & 2,40 \\
\hline
\end{tabular}

Table 1 presents measurements of the cross-sectional width and channel depth are repeated 3 (three) times each, the 
measurement data is shown in Table 1 with the average crosssectional width value of $30 \mathrm{~cm}$ and the average channel depth is $20 \mathrm{~cm}$.

TABLE II.

TURBINE ROTATION DATA

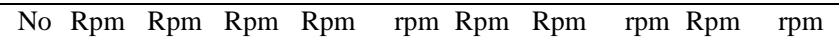

\begin{tabular}{ccccccccccc}
\hline 1 & 160 & 200 & 170 & 210 & 200 & 180 & 210 & 210 & 210 & 210 \\
\hline 2 & 205 & 210 & 190 & 200 & 160 & 210 & 210 & 200 & 190 & 200 \\
& & & & & & & & & & \\
\hline 3 & 210 & 165 & 210 & 180 & 190 & 205 & 175 & 196 & 190 & 200 \\
& & & & & & & & & & \\
\hline 4 & 180 & 170 & 205 & 185 & 210 & 210 & 205 & 195 & 180 & 190 \\
& & & & & & & & & & \\
\hline 5 & 203 & 210 & 210 & 190 & 210 & 190 & 210 & 210 & 210 & 180 \\
& & & & & & & & & & \\
\hline 6 & 210 & 175 & 200 & 190 & 185 & 200 & 180 & 200 & 200 & 200 \\
& & & & & & & & & & \\
\hline 7 & 190 & 205 & 160 & 210 & 195 & 210 & 160 & 210 & 160 & 210 \\
& & & & & & & & & & \\
\hline 8 & 200 & 210 & 190 & 200 & 210 & 200 & 205 & 200 & 203 & 200 \\
& & & & & & & & & & \\
\hline 9 & 210 & 170 & 190 & 175 & 182 & 196 & 168 & 205 & 200 & 203 \\
& & & & & & & & & & \\
\hline Aver & 196 & 190 & 191 & 193 & 193 & 200 & 191 & 202 & 193 & 199 \\
age &, 44 &, 56 &, 67 &, 33 &, 56 &, 11 &, 44 &, 89 &, 67 &, 22 \\
\hline valu & 196 & 190 & 191 & 193 & 193 & 200 & 191 & 202 & 193 & 199 \\
es & 4,4 & 5,5 & 6,6 & 3,3 & 5,5 & 1,1 & 4,4 & 8,8 & 6,6 & 2,2 \\
& 4 & 6 & 7 & 3 & 6 & 1 & 4 & 9 & 7 & 2 \\
\hline
\end{tabular}

The investigation of the flow capacity was carried out in the Saruan waterfall area, expected to have a good capacity. The measurements were carried out at four points taken as the basis for the calculation at the four-channel cross-sections. Table 2 presents the measurement results.

C. Cross-sectional area and flow discharge capacity

The cross-sectional area of the channel is determined by 2 (two) parameters, the width, and height of the cross-section.

$$
\begin{gathered}
A=B \times H \\
A=0.42 \times 0.57 \\
\mathrm{~A}=0,2394 \mathrm{~m} 2
\end{gathered}
$$

Flow discharge capacity can be formulated by multiplying 2 (two) parameters, namely; the cross-sectional area of $0,2394 \mathrm{~m} 2$ and flow rate of $3.2228 \mathrm{~m} / \mathrm{sec}$.

$$
\begin{gathered}
\mathrm{Q}=\mathrm{v} \times \mathrm{A} \\
\mathrm{Q}=3.2228 \times 0.2394 \\
\mathrm{Q}=0.7618
\end{gathered}
$$

Calculation of channel cross-sectional area and flow discharge capacity, can be seen in table 3 below.

TABLE III. DATA FLOW

\begin{tabular}{lllll}
\hline No & Description & Symbol & Unit & Dimension \\
\hline 1 & Effective fall height & $\mathrm{H}$ & $\mathrm{M}$ & 2 \\
\hline 2 & Channel area & $\mathrm{A}$ & $\mathrm{m}^{2}$ & 0,2394 \\
\hline 3 & Flowrate & $\mathrm{V}$ & $\mathrm{m} / \mathrm{dt}$ & 3,223 \\
\hline 4 & Water density & $\rho$ & $\mathrm{kg} / \mathrm{m}^{3}$ & 1000 \\
\hline 5 & Gravity & $\mathrm{G}$ & $\mathrm{m} / \mathrm{dt}$ & 9,81 \\
\hline 6 & Efficiency & $\mathrm{n}$ & - & 0,8 \\
\hline $\mathbf{7}$ & Flow & $\mathrm{Q}$ & $\mathrm{m} / \mathrm{dt}$ & 0,7618 \\
\hline
\end{tabular}

\section{Power Available}

The power available can be determined four parameters, namely the density of water, gravity, flowrate, and effective fall height.

$$
\begin{gathered}
P a=p \times g \times Q \times H \\
P a=1000 \times 9.81 \times 0.7618 \times 2 \\
P a=14946.516 \mathrm{~W} \\
P a=14.946 \mathrm{~kW}
\end{gathered}
$$

\section{E. Turbine Power}

The value of turbine power is obtained from:

$$
\begin{aligned}
r & =x \text { D Pulley } \\
& =x(20 \mathrm{in}) \\
& =10 \mathrm{in} \\
& =10 \times 2,54 \\
& =25,4 \mathrm{~cm} \\
& =0,254 \mathrm{~m}
\end{aligned}
$$

Prediction of Archimedes screw turbine power capacity is determined by adopting some of these parameters.

$$
\begin{aligned}
& \mathrm{Pt}=200 \times 0,254 \times 2 \times 3,14 \times 7 / 60 \\
& \mathrm{Pt}=40,004 \times 8,932672 / 60 \\
& \mathrm{Pt}=40,044 \times 0,148 \\
& \mathrm{Pt}=5,926 \mathrm{Watt} \\
& \mathrm{Pt}=5,9 \mathrm{~kW} .
\end{aligned}
$$

\section{CONCLUSIONS}

Based on the measurement value data and the calculation, the maximum channel cross-section speed on the surface flow obtained is $10.79 \mathrm{~m} / \mathrm{sec}$, and the minimum channel bottom speed is $3.2228 \mathrm{~m} / \mathrm{sec}$. The power of available flow at the channel is $5.9 \mathrm{~kW}$, greater than the power produced on the turbine that is $4.7 \mathrm{~kW}$. The time limitation in conducting the research results in data limitation. This aspect suggested that future research should consider to carry out more rigorous research in Micro Hydro Power Plant.

\section{REFERENCES}

[1] I. Comendant, I. Prepelita, and L. Turcuman, "Identifying the opportunity to meet the Republic of Moldova Electricity Demand by Combining Renewable Energy Sources and Energy Storage Systems," in 2019 International Conference on Electromechanical and Energy Systems (SIELMEN), 2019, pp. 1-6.

[2] Y. Z. Arief, N. A. A. A. Halim, and M. H. I. Saad, "Optimization of Hybrid Renewable Energy in Sarawak Remote Rural Area Using HOMER Software," in 2019 International UNIMAS STEM 12th Engineering Conference (EnCon), 2019, pp. 1-5.

[3] F. C. Jong, M. M. Ahmed, and D. L. H. Aik, "Integration of Renewable Energy Sources Optimization in Sarawak Using GIS and MCDM-AHP," in 2019 International UNIMAS STEM 12th Engineering Conference (EnCon), 2019, pp. 65-70.

[4] A. Nath, S. Barua, and N. Mohammad, "Electric Power GenerationMix for Bangladesh and Its Future," in 2019 International Conference on Electrical, Computer and Communication Engineering (ECCE), 2019, pp. 1-4. 
[5] A. K. Mathur and S. Singh, "Status of India's Renewable Energy Commitments for the Paris Agreement," in 2019 International Conference on Power Generation Systems and Renewable Energy Technologies (PGSRET), 2019, pp. 1-5.

[6] U. K. Kalla, B. Singh, S. S. Murthy, C. Jain, and K. Kant, "Adaptive Sliding Mode Control of Standalone Single-Phase Microgrid Using Hydro, Wind, and Solar PV Array-Based Generation," IEEE Trans. Smart Grid, vol. 9, no. 6, pp. 6806-6814, Nov. 2018.

[7] G. Pathak, B. Singh, and B. K. Panigrahi, "Wind-Hydro Microgrid and Its Control for Rural Energy System," IEEE Trans. Ind. Appl., vol. 55, no. 3, pp. 3037-3045, May 2019.

[8] T. Li et al., "Optimized Operation of Hybrid System Integrated With MHP, PV and PHS Considering Generation/Load Similarity,” IEEE Access, vol. 7, pp. 107793-107804, 2019.

[9] L. I. Vuta, G. E. Dumitran, B. Popa, M. A. Diminescu, and E. I. Tica, "Hidden Hydro Related with Non-Powered Dams in Romania," in 2019 International Conference on ENERGY and ENVIRONMENT (CIEM), 2019, pp. 413-417.

[10] R. Aarthi, R. B. Kumar, T. Ravichandran, and S. Giridharan, "A Smart Hydro Electric Generator in Home Based On IOT," in 2019 5th International Conference on Advanced Computing \& Communication Systems (ICACCS), 2019, pp. 1036-1038.

[11] Y. Sun et al., "The Role of Pumped Hydro Storage in Supporting Modern Power Systems: A Review of the Practices in China," in 2019 IEEE Innovative Smart Grid Technologies - Asia (ISGT Asia), 2019, pp. 1613-1617.

[12] H.-T. Zhang, H. Wang, Y. Ding, and N. Wang, "A Novel Strategy for Wind-Solar-Hydro Complimentary Real-time Scheduling and Control," in 2019 IEEE Innovative Smart Grid Technologies - Asia (ISGT Asia), 2019, pp. 3782-3787.

[13] L. Wang et al., "Research Prospect of Cascade Hydro-photovoltaicpumped Storage Hybrid Power Generation Technology," 2019 IEEE PES Innov. Smart Grid Technol. Asia, ISGT 2019, pp. 42524255, 2019.

[14] D. Apostolopoulou and M. McCulloch, "Optimal Short-Term Operation of a Cascaded Hydro-Solar Hybrid System: A Case Study in Kenya," IEEE Trans. Sustain. Energy, vol. 10, no. 4, pp. 1878 1889, Oct. 2019.

[15] Shamsullaqa, Shatrughn, A. Pandey, A. Iqbal, A. K. Mishra, and M Aslam Husain, "Economic Feasibility Analysis of Solar PV Generation at REC Ambedkar Nagar," in 2019 IEEE International Conference on Electrical, Computer and Communication Technologies (ICECCT), 2019, vol. 5, pp. 1-6.

[16] Zhao Liang, Yu Ruoying, Chen Peijin, and Han Bin, "Study on Deep-Peak Regulation of Coal-Gas-Hydro Power System in Portugal when Considering High Wind Penetration," in 8th Renewable Power Generation Conference (RPG 2019), 2019, vol. 2019, no. CP764, pp. 410 (9 pp.)-410 (9 pp.).

[17] Danyang Zhao, Wei Yan, Cheng Luo, and Tian Luo, "MILP Model for Annual Power and Energy Balance of Hydro-Thermal-Wind Power System Considering RPS Mechanism," in 8th Renewable Power Generation Conference (RPG 2019), 2019, vol. 2019, no. CP764, pp. 210 (7 pp.)-210 (7 pp.).
[18] C. Cutajar, T. Sant, D. Buhagiar, and R. N. Farrugia, "Modelling of a hybrid floating wind, energy storage and desalination unit," 2019 Offshore Energy Storage Summit, OSES 2019, pp. 1-11, 2019.

[19] A. Troullaki, K. Latoufis, P. Marques, F. Freire, and N. Hatziargyriou, "Life Cycle Assessment of Locally Manufactured Small Wind Turbines and Pico-Hydro Plants," in 2019 International Conference on Smart Energy Systems and Technologies (SEST), 2019, pp. 1-6.

[20] R. K. Vishnoi and L. P. Joshi, "Challenges in Reliable Power System Planning and Management with Large Scale Infusion of Renewable Sources in India," in 2019 IEEE PES GTD Grand International Conference and Exposition Asia (GTD Asia), 2019, pp. 63-67.

[21] G. Magdy, E. A. Mohamed, G. Shabib, A. A. Elbaset, and Y. Mitani, "SMES based a new PID controller for frequency stability of a real hybrid power system considering high wind power penetration," IET Renew. Power Gener., vol. 12, no. 11, pp. 1304-1313, Aug. 2018.

[22] S. M. H. Ali, M. Lenzen, and J. Huang, "Shifting air-conditioner load in residential buildings: benefits for low-carbon integrated power grids," IET Renew. Power Gener., vol. 12, no. 11, pp. 13141323, Aug. 2018.

[23] D. A. Tejada-Arango, S. Wogrin, and E. Centeno, "Representation of Storage Operations in Network-Constrained Optimization Models for Medium- and Long-Term Operation," IEEE Trans. Power Syst., vol. 33, no. 1, pp. 386-396, Jan. 2018.

[24] M. Alvarez, S. K. Ronnberg, J. Bermudez, J. Zhong, and M. H. J. Bollen, "A Generic Storage Model Based on a Future Cost Piecewise-Linear Approximation,” IEEE Trans. Smart Grid, vol. 10, no. 1, pp. 878-888, 2019.

[25] R. Dhakal et al., "Prospects of Off Grid Energy Generation through Low Head Screw Turbine in Nepal," in 2018 7th International Conference on Renewable Energy Research and Applications (ICRERA), 2018, vol. 5, pp. 537-543.

[26] A. M. Durrani, O. Mujahid, and M. Uzair, "Micro Hydro Power Plant using Sewage Water of Hayatabad Peshawar," in 2019 15th International Conference on Emerging Technologies (ICET), 2019, pp. 1-5.

[27] A. Khan, A. Khattak, A. Ulasyar, K. Imran, and M. A. Munir, "Investigation of Archimedean Screw Turbine for Optimal Power Output by Varying Number of Blades," in 2019 International Conference on Electrical, Communication, and Computer Engineering (ICECCE), 2019, no. July, pp. 1-6.

[28] A. Raza, D. Xu, M. S. Mian, and J. Ahmed, “A micro hydro power plant for distributed generation using municipal water waste with archimedes screw," in INMIC, 2013, pp. 66-71.

[29] E. Buffa, L. Ferraris, P. Ferraris, and E. Poskovic, “Archimedes screws for micro hydro induction generation: Effects of the adoption of a frequency converter," in 2015 International Conference on Clean Electrical Power (ICCEP), 2015, no. 2, pp. 633-638.

[30] S. Simmons and W. Lubitz, "Archimedes screw generators for sustainable energy development," in 2017 IEEE Canada International Humanitarian Technology Conference (IHTC), 2017, pp. 144-148. 